Picture Srory

\title{
A RARE CASE OF DIPHALLIA ASSOCIATED WITH ANORECTAL AND VERTEBRAL MALFORMATIONS
}

MHSM Hassan ${ }^{1}$, S Basnayake ${ }^{2}$

Key words: Diphallia, Congenital malformation

\section{INTRODUCTION}

Diphallia is a rare urogenital tract malformation characterized by complete or partial penile duplication with an estimated incidence of 1 per 5 to 6 million live births. ${ }^{1}$ First case was published in 1609 and till now only around 100 cases have been reported worldwide. ${ }^{1}$

Diphallia is often associated with multiple anomalies such as anorectal malformations, urinary tract abnormalities, vertebral deformities, bladder or cloacal extrophy and congenital heart diseases. In severe cases pubic symphysis diastasis, imperforated or duplicated anus, recto sigmoidal duplication and inguinal hernia may be observed.

It is proposed that diphallia occurs between $23^{\text {rd }}$ to $25^{\text {th }}$ days of gestation when environmental precipitants like drugs, infections, chemical stress impair the normal function of the caudal cell mass of the mesoderm. ${ }^{1,3}$

\section{CASE REPORT}

A baby boy was born to a 29 year old mother in her third pregnancy with two healthy living children. There were no antenatal complications and her ultra sound scan including anomaly scan did not reveal any significant fetal anomalies. Baby was delivered by elective caesarian section due to past section at 37 weeks of period of gestation. Baby was born in good conditions and his APGAR scores were 8,9,10 at 1 minute, 5 minutes and 10 minutes respectively. Baby weighed $2.9 \mathrm{~kg}$, had a length of $45 \mathrm{~cm}$ and $\mathrm{OFC}$ of $34 \mathrm{~cm}$.
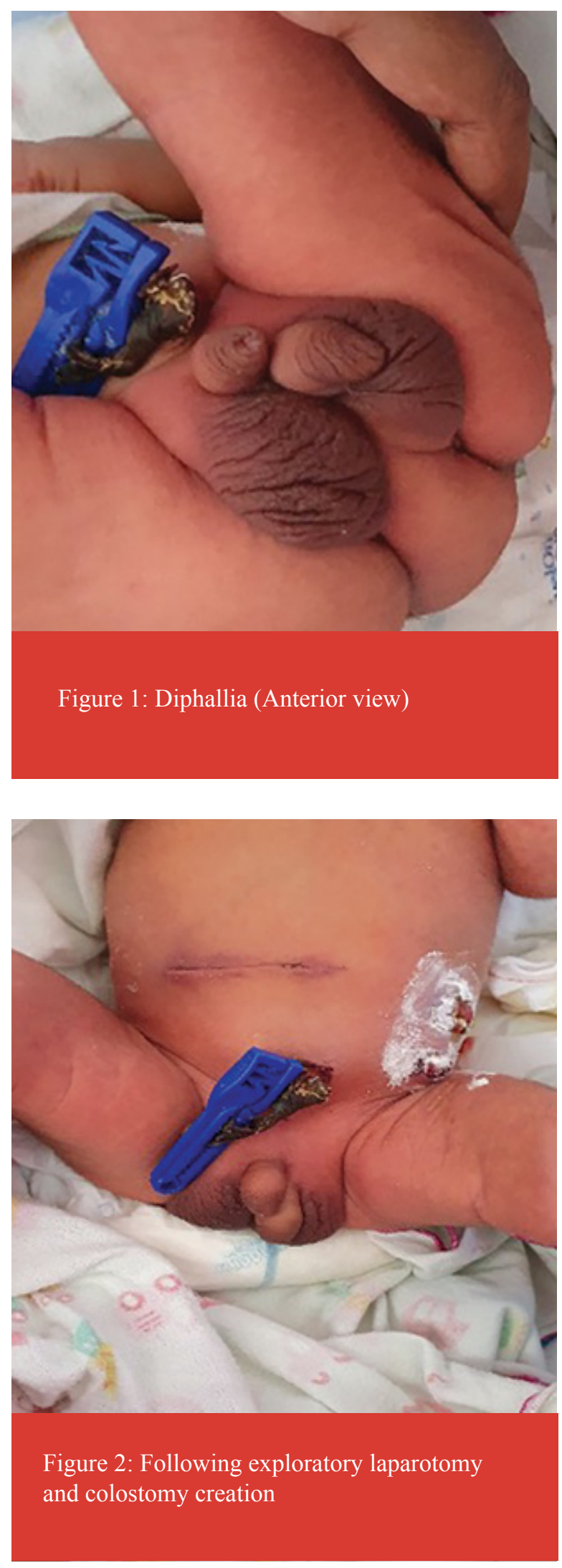


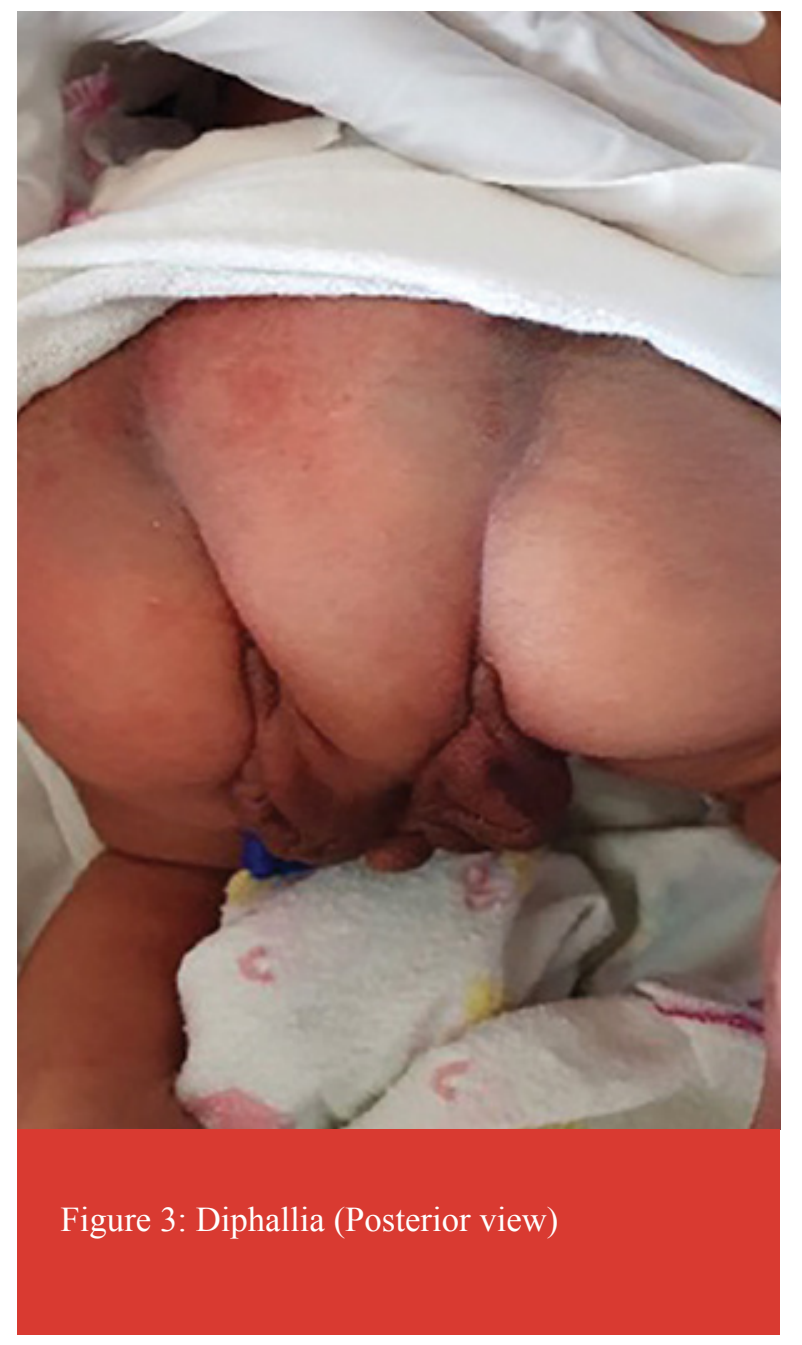

During the inspection complete penile duplication, bifid scrotum with bilateral undescended testes and duplicated dimple like anal margins with imperforation were noted. In addition a soft tissue swelling was found over the sacral spine without any external deformities. (figure 1,2) However bilateral lower limb movements were persevered. Apart from above anomalies rest of the neonatal examination was normal.

Ultra sound scan KUB (kidney, ureters and bladder) revealed a cross fused left sided renal ectopia and right sided testes was visualized in inguinal canal but left side testes was not identified. Ultra sound scan of spine showed possible tethered cord with distal diastomatomyelia. Chest X-ray and 2D Echocardiogram were normal. Baby is awaiting for MRI brain and spine. Free urinary flow was noted during catheter insertion of both urethral openings.
Baby has undergone exploratory laparotomy and colostomy creation under general anesthesia in day 2 of life. He is presently awating multidisciplinary review.

\section{DISCUSSION}

Diphallia is a rare congenital abnormality. Extensive investigations are needed in all cases to identify associated other congenital malformations. Treatment should always be individualized according to the degree of penile duplication and extend of the associated anomalies ${ }^{2}$.Management of these patients will be a challenge for the Multidisciplinary team.

\section{REFERENCES}

01. Frolov A, Tan Y, Rana MW, Martin J R . A rare case of human diphallia associated with hypospadias. Case reports in urology. 2018 Jun 13;2018.

02. Gyftopoulos K, Wolffenbuttel KP, Nijman RJ. Clinical and embryologic aspects of penile duplication and associated anomalies. Urology. 2002 Oct 1;60(4):675-9.

03. Kundal VK, Gajdhar M, Shukla AK, Kundal R. A rare case of isolated complete diphallia and review of the literature. Case Reports. 2013 Feb 13;2013:bcr2012008117.

\section{${ }^{1}$ Senior Registrar in Neonatology \\ Lady Ridgeway Hospital for Children, Colombo \\ ${ }^{2}$ Consultant Neonatologist \\ Lady Ridgeway Hospital for Children, Colombo}

Corresponding author:

$S$ Basnayake

shyamabas@gmail.com 